\title{
Web-Based Peer Support Interventions for Adults Living With Chronic Conditions: Scoping Review
}

Saima N Hossain ${ }^{1 *}$, BSc; Susan B Jaglal ${ }^{1,2,3,4^{*}}$, PhD; John Shepherd ${ }^{2 *}$, MBA; Laure Perrier ${ }^{5^{*}}$, PhD; Jennifer R Tomasone $^{6 *}, \mathrm{PhD}$; Shane N Sweet ${ }^{6 *}, \mathrm{PhD}$; Dorothy Luong ${ }^{1 *}, \mathrm{MSc}$; Sonya Allin ${ }^{3 *}, \mathrm{PhD}$; Michelle L A Nelson ${ }^{4,7^{*}}, \mathrm{PhD}$; Sara J T Guilcher ${ }^{4,8}$, PT, PhD; Sarah E P Munce ${ }^{9 *}, \mathrm{PhD}$

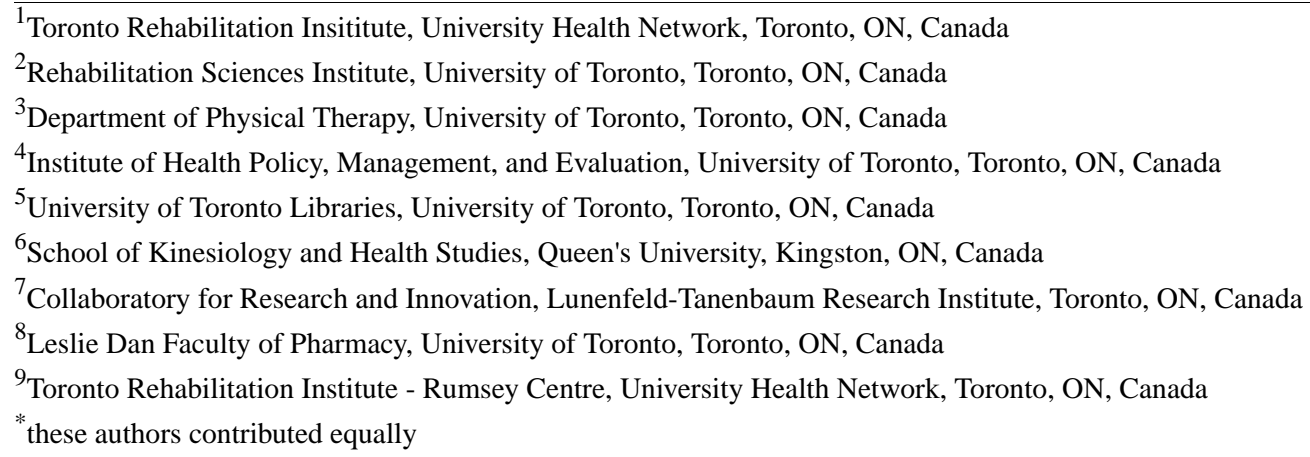

Corresponding Author:

Sarah E P Munce, PhD

Toronto Rehabilitation Institute - Rumsey Centre

University Health Network

345 Rumsey Road

Toronto, ON, M4G 1R7

Canada

Phone: 14165973422 ext 5313

Email: sarah.munce@uhn.ca

\section{Abstract}

Background: Globally, 1 in 3 adults live with multiple chronic conditions. Thus, effective interventions are needed to prevent and manage these chronic conditions and to reduce the associated health care costs. Teaching effective self-management practices to people with chronic diseases is one strategy to address the burden of chronic conditions. With the increasing availability of and access to the internet, the implementation of web-based peer support programs has become increasingly common.

Objective: The purpose of this scoping review is to synthesize existing literature and key characteristics of web-based peer support programs for persons with chronic conditions.

Methods: This scoping review follows the PRISMA (Preferred Reporting Items for Systematic Reviews and Meta-Analyses) extension for scoping reviews guidelines. Studies were identified by searching MEDLINE, CINAHL, Embase, PsycINFO, and the Physiotherapy Evidence Database. Chronic diseases identified by the Public Health Agency of Canada were included. Our review was limited to peer support interventions delivered on the web. Peers providing support had to have the chronic condition that they were providing support for. The information abstracted included the year of publication, country of study, purpose of the study, participant population, key characteristics of the intervention, outcome measures, and results.

Results: After duplicates were removed, 12,641 articles were screened. Data abstraction was completed for 41 articles. There was a lack of participant diversity in the included studies, specifically with respect to the conditions studied. There was a lack of studies with older participants aged $\geq 70$ years. There was inconsistency in how the interventions were described in terms of the duration and frequency of the interventions. Informational, emotional, and appraisal support were implemented in the studied interventions. Few studies used a randomized controlled trial design. A total of 4 of the 6 randomized controlled trials reported positive and significant results, including decreased emotional distress and increased health service navigation, self-efficacy, social participation, and constructive attitudes and approaches. Among the qualitative studies included in this review, there were several positive experiences related to participating in a web-based peer support intervention, including increased compassion and improved attitudes toward the individual's chronic condition, access to information, and empowerment. 
Conclusions: There is limited recent, high-level evidence on web-based peer support interventions. Where evidence exists, significant improvements in social participation, self-efficacy, and health-directed activity were demonstrated. Some studies incorporated a theoretical framework, and all forms of peer support-emotional, informational, and appraisal support-were identified in the studies included in this review. We recommend further research on web-based peer support in more diverse patient groups (eg, for older adults and chronic conditions outside of cancer, cardiovascular disease, and HIV or AIDS). Key gaps in the area of web-based peer support will serve to inform the development and implementation of future programs.

(JMIR Rehabil Assist Technol 2021;8(2):e14321) doi: 10.2196/14321

\section{KEYWORDS}

online; peer support; self-management; chronic conditions; scoping review

\section{Introduction}

\section{Background}

In Canada, 1 in 5 adults live with cardiovascular disease, cancer, diabetes, or chronic respiratory disease [1]. These chronic conditions account for $65 \%(153,000)$ of deaths in Canada each year [2] and are the leading causes of death globally [1]. These chronic conditions account for $42 \%$ of direct health care costs in Canada or Can $\$ 39$ billion (US $\$ 32$ billion) per year [2]. The total economic burden is a combination of medical costs (Can $\$ 38.9$ billion; US $\$ 31.9$ billion) and indirect productivity losses (Can $\$ 54.4$ billion; US $\$ 44.6$ billion) [2]. Globally, 1 in 3 adults live with multiple chronic conditions [3], and among Americans aged $\geq 65$ years, approximately 3 in 4 adults have multiple chronic conditions [4]. Thus, effective interventions are needed to prevent and manage these chronic conditions and to reduce the associated health care costs.

Teaching effective self-management practices to people with chronic diseases is one strategy to address the burden of chronic conditions [4]. For example, in the United States, the Affordable Care Act encourages chronic disease self-management practices [5]. The Affordable Care Act offers reimbursement opportunities for providers of chronic disease management services and provides government support for the development of programs aimed at self-management [5]. In the context of chronic conditions, self-management refers to a patient's ability to manage various physical and psychosocial ailments and lifestyle changes [6,7]. Previous research has indicated that peers can support chronic disease self-management [8] in a cost-effective manner [8-10]. For example, an economic evaluation conducted by Graffy et al [11] found lower total health care costs due to decreased hospitalization expenses among individuals with diabetes who had received peer support (group or one-to-one delivery) compared with those among control groups.

In the context of chronic disease management, peer support refers to providing assistance to other individuals with similar conditions [8,11]. Programs with an associated peer support component have 3 commonalities: support for emotional, informational, and appraisal needs [12]. Emotional support includes caring, empathy, and encouragement of the individual. Informational support refers to providing advice, suggestions, and alternative actions. Appraisal support involves affirmation, constructive feedback, and the provision of information useful for self-evaluation [13]. Peer support programs can be delivered using a wide variety of modalities, including face-to-face, telephone, or internet. With the increasing availability and access to the internet (eg, over 32 million people in Canada [14] and $55.1 \%$ of the world's population [15]), the implementation of web-based peer support programs, in particular, has become increasingly common and relevant [14-16].

\section{Objective}

With the increasing implementation of web-based peer support interventions, there is a need to examine the characteristics of these interventions and determine the gaps in this emerging literature. The purpose of this scoping review is to synthesize the existing literature and key characteristics (eg, duration; frequency; delivery setting; type of intervention; type of support provided, including emotional, informational, and appraisal; and underlying theories for the intervention, behavior change techniques, or mechanisms) of web-based peer support programs for persons with chronic conditions.

\section{Methods}

\section{Overview}

The methodology for this scoping review has been previously published [17], but it is briefly described below. This scoping review follows the PRISMA (Preferred Reporting Items for Systematic Reviews and Meta-Analyses) extension for scoping reviews guidelines [18].

\section{Search Strategy and Information Sources}

A comprehensive literature search was conducted by an experienced librarian (LP) with input from the investigators. Literature search strategies were developed using medical subject headings and text words related to chronic conditions and peer support interventions. The MEDLINE search has been previously published in our protocol paper [17]. The search was initially run on May 6 and 8, 2017, and rerun on June 6, 2018. The following databases were searched: MEDLINE (OVID), MEDLINE In-Process \& Other Non-Indexed Citations (OVID), MEDLINE Epub Ahead of Print (OVID), Embase (OVID), CINAHL (EBSCOhost), Physiotherapy Evidence Database, and PsycINFO (OVID). A validated search filter for identifying age-specific studies that specifically identified citations for adults was added to MEDLINE, Embase, and CINAHL. Duplicates were removed by using EndNote's duplicate identification feature and by reviewing records manually. Searches were limited to studies conducted from 2012 to 2018 and English language studies. Studies were included from this 6-year window to increase the relevance to the current health care context. Due to time and resource constraints, we were 
unable to extend the search beyond this 6-year window. In addition, for feasibility considerations, no hand searching was performed.

\section{Eligibility Criteria}

Chronic diseases identified by the Public Health Agency of Canada (PHAC), including cancer, heart disease (cardiovascular disease), hypertension, stroke, chronic respiratory diseases (asthma, chronic obstructive pulmonary disease, and sleep apnea), diabetes, inflammatory bowel diseases (Crohn disease and ulcerative colitis), multiple sclerosis, neurological conditions (eg, Alzheimer disease and other dementias), cerebral palsy, epilepsy, multiple sclerosis, Parkinson disease or parkinsonism, traumatic brain injury, traumatic spinal cord injury, arthritis, and osteoporosis, were included [19]. This list of chronic conditions is consistent with other global definitions of chronic conditions (eg, the World Health Organization) [20]. This review included studies involving individuals with chronic conditions, including comorbid mental illness. Studies must have reported on adults (age $\geq 18$ years) with one of the previously listed PHAC chronic conditions or HIV or AIDS. Although mental illness is included in the PHAC list of chronic diseases, it was excluded for the purposes of this review because peer support interventions for this specific group may have unique features (eg, coping with stigma, including self-blaming, guilt, and shame) that may not be generalizable to other patient populations with chronic disease [21,22]. Similarly, although not included in the PHAC list, due to the high volume of web-based peer support interventions reported on individuals with HIV or AIDS, it was included in this review's list of chronic diseases [23]. In addition, including HIV or AIDS in this list of inclusion criteria was further rationalized by a similar review conducted by Lauckner et al [12], who examined peer support for people with chronic conditions in rural areas.

Our review was limited to peer support interventions delivered on the web. Studies were included if a web-based peer component was part of their intervention. Support must be provided by a peer who has the same chronic condition. Examples of web-based peer interventions include video-based discussions using formats such as Skype, social media peer interactions, and text messages from peers. Peer-led interventions that used a web-based modality in combination with another modality, such as telephone or face-to-face interventions, were included. Interventions describing professional-led groups involving community health workers who are not peers (eg, health care professionals), e-counseling service interventions, studies reporting on outcomes of usability testing but not the outcomes of the participants, support group interventions, and telephone-based peer support interventions were excluded. In addition, studies were excluded if they described the benefits of using the internet generally but did not describe an intervention and the reported outcomes of that intervention. If the study described an intervention that had a combination of peer- and professional-led support, it was excluded.

To further describe the types of articles that were included and excluded in this review, we provide an example of 1 study that was included and 2 that were excluded.
The study Development of Trust in an Online Breast Cancer Forum: A Qualitative Study by Lovatt et al [24] was included in this review. This study explored the breast cancer care forum by collecting discussion threads and analyzing them. In this case, the web-based forum was the modality for delivering peer support. The study The Emerging Diabetes Online Community by Hilliard et al [25] was excluded from our study. Although the study reported on multiple web-based platforms (eg, forums, blogs, video or podcasts, and social media websites used by individuals living with diabetes), the study did not report on the outcomes or experiences of a specific web-based peer support intervention. Finally, the study Online support for individuals with spinal cord injuries: An ethnographic investigation by O'Riley et al [26] was excluded. This study involved interviews to explore how individuals with a spinal cord injury could benefit or might use the internet for support. However, no specific peer support intervention had been implemented. Finally, all study designs (eg, observational studies, randomized controlled trials, and qualitative studies) were included.

\section{Study Selection}

The studies were screened using a 2-step process. First, the titles and abstracts were screened in duplicate by independent reviewers, followed by full-text screening, which was conducted in duplicate. Both level 1 and level 2 screening followed the same screening form. DistillerSR reference manager was used by independent reviewers to keep track of the decisions. Discrepancies were resolved by discussion between reviewers and, if necessary, the senior author (SEPM).

\section{Data Abstraction}

Data abstraction forms developed by the research team were used. The information abstracted included year of publication, country of study, purpose of the study, participant population (eg, chronic condition, age, sex, gender, and education), key characteristics of the intervention (eg, duration; frequency; delivery setting; type of intervention; type of support provided, including emotional, informational, and appraisal; underlying theories for the intervention, behavior change techniques, or working mechanisms; and context), outcome measures, and results. Results including $P$ values were collected for the quantitative studies; themes and subthemes were abstracted for the qualitative studies. For qualitative studies, similar themes across studies were clustered together by the lead author (SNH) in consultation with the senior author. Data abstraction was conducted independently in duplicate.

\section{Results}

\section{Overview}

The literature searches yielded 13,286 articles. After duplicates were removed, 12,641 articles were screened. After level 1 screening, 368 articles were included in the full-text screening. Of these 368 items, 5 oral presentations and 37 abstracts from conferences were excluded, as it was not possible to obtain full-text articles. A total of 9 protocol papers were excluded because there were no data on the results of the reported interventions. After level 2 screening, data abstraction was completed for 41 articles. The reasons for article exclusion 
varied but were primarily related to not having a peer support component implemented in the studied intervention. Further rationale as to why articles were excluded are described above within the Eligibility Criteria section. The PRISMA flowchart is shown in Figure 1.

Figure 1. PRISMA (Preferred Reporting Items for Systematic Reviews and Meta-Analyses) flowchart.
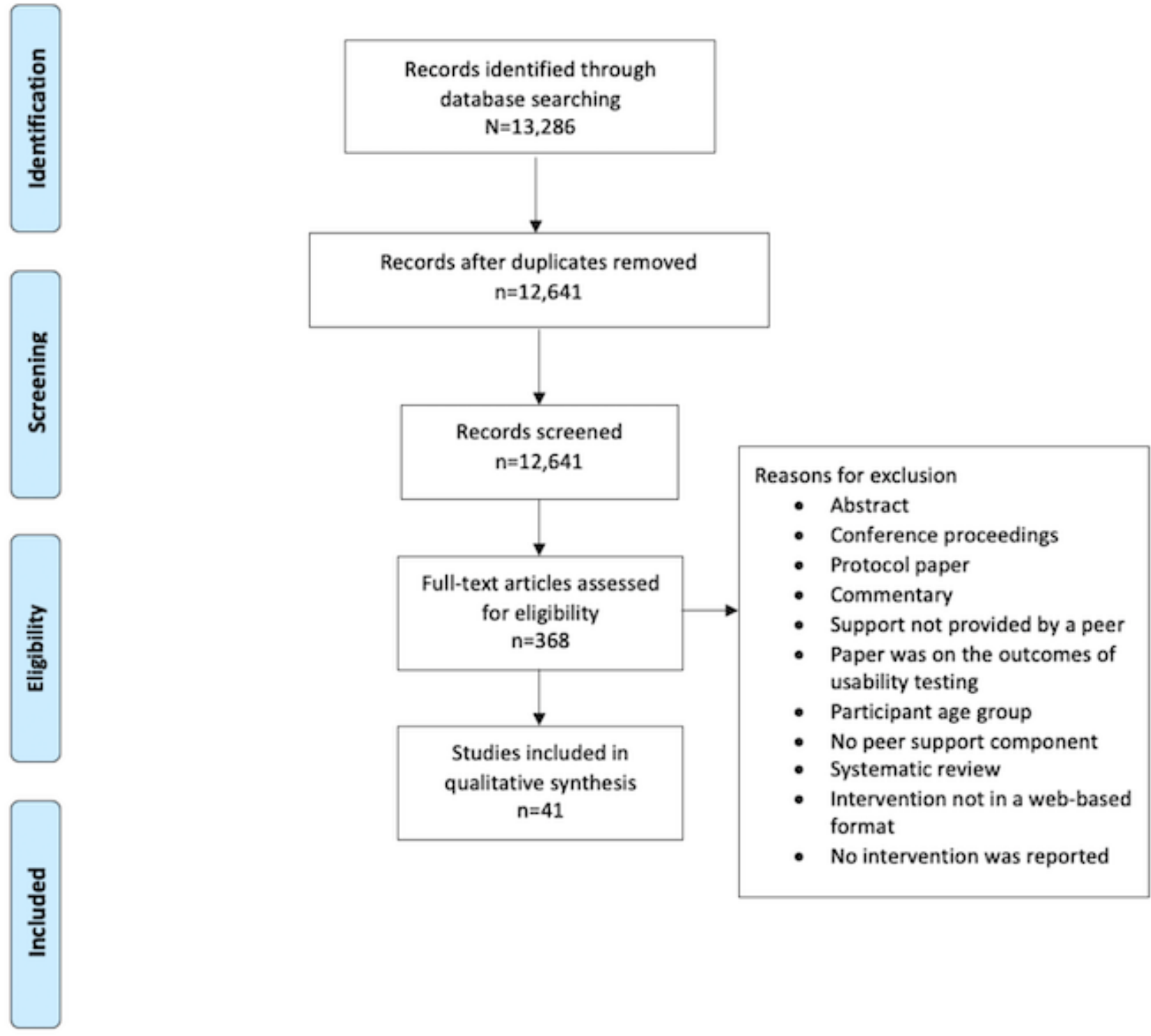

\section{Study Characteristics}

A summary of the included studies with information on patient characteristics, peer support intervention characteristics, outcome measures, and impact is included in Multimedia Appendix 1 [24,27-65]. A total of 18 studies were conducted in the United States, 5 in Australia, 5 in the United Kingdom, and 4 in Canada. The remaining 9 studies were conducted in Finland, Sweden, Germany, China, Italy, South Africa, and Sweden.

Around half of the studies included in this review were qualitative $(20 / 41,49 \%)$. Specifically, 14 of these studies analyzed content posted on web-based discussion forums, whereas the other 6 were qualitative studies that reported on the experiences of the patients participating in a web-based peer support program. The quantitative studies included in the review were randomized controlled trials $(6 / 41,14 \%)$ and cross-sectional studies using a survey design $(8 / 41,19 \%)$. The remaining studies were mixed methods studies $(4 / 41,10 \%)$, nonrandomized controlled trials in which matched controls served as the comparison group, quasi-experimental studies $(1 / 41,2 \%)$, and integrative reviews $(1 / 41,2 \%)$.

There were various limitations to the included studies. Among the randomized controlled trials, there were small sample sizes (sample sizes ranged from 30 to 227) [27-32], weak validity and reliability of the measures included [30], and the type of control group used in the trial (eg, control condition involved usual treatment) [31]. In terms of the limitations of the qualitative studies, some examples included selection bias [33], limited transferability of the study findings [34], and the potential for information to be removed by a moderator [35].

\section{Patient Characteristics}

The studies included participants with cancer $(15 / 41,36 \%)$, diabetes $(9 / 41,21 \%)$, and HIV (7/41, 17\%). The remaining 10 studies included participants with arthritis $(2 / 41,4 \%)$, atrial 
fibrillation $(1 / 41,2 \%)$, chronic pain $(1 / 41,2 \%)$, inflammatory bowel disease $(1 / 41,2 \%)$, multiple sclerosis $(2 / 41,4 \%)$, peripartum cardiomyopathy $(1 / 41,2 \%)$, and stroke $(2 / 41,4 \%)$. The individuals included in the studies were aged between 19 and 70 years. This broad range of age groups made it difficult to summarize the studies based on specific age groups. In the majority of the studies, the ratio of male to female participants varied, except in studies on chronic conditions that are of higher prevalence in a specific sex (eg, breast cancer and prostate cancer) $[24,33,36-39,66]$. Specifically, of the 3 studies that reported on breast cancer, 2 reported that all participants were female.

\section{Key Characteristics of the Peer Support Interventions}

This section outlines the following key characteristics of the studies on web-based peer support interventions included in our review: duration; frequency; delivery setting; type of intervention; type of support provided, including emotional, informational, and appraisal; and underlying theories for the intervention, behavior change techniques, or mechanisms.

\section{Duration and Frequency}

For the included studies, the duration and frequency of the interventions varied. Of the 41 included studies, 15 (36\%) had interventions lasting for 2 weeks to 16 weeks [27-31,33,40-47,66], whereas some interventions $(2 / 41,4 \%)$ lasted for $1-2$ years $[48,49]$. The frequency of peer interaction ranged from weekly interactions to monthly updates [27,29-31,41,43,46,48].

\section{Delivery Setting}

A total of 15 of the 41 studies described a web-based discussion board as the means of delivering the intervention [24,32-35,39,40,43,45,50-54,66]. Moreover, 9 of the 41 studies used an existing social network site such as Facebook, Twitter, or Myspace [29,36,37,44,47,48,55-57]. In addition, 6 of the 41 studies described a unique web-based platform that consisted of different components such as information modules, live chats, and web-based discussion boards to create a community of participants involved in web-based discussions $[30,31,38,49,58,59]$. Furthermore, 5 of the 41 studies used a combination of delivery mechanisms, including Skype, social networking sites, forums, telephone, and face-to-face [42,60-63]. One of the 41 studies used Skype video conferencing [41], whereas another study used another web-based video conferencing software [27]. A total of 2 of the 41 studies used a web-based chatroom interface [64,65], and an additional 2 studies used text messaging as a means of peer support (Multimedia Appendix 2) [28,46].

\section{Types of Interventions}

Of the included studies, 21 of the 41 studies reported on using a group-type intervention [27,29-33,35,40,43-45,47-49,51, $53,55,57-59,64]$. A total of 5 of the 41 included studies had web-based peer support delivered through a one-on-one format $[24,28,39,41,46]$. In the remaining studies $(15 / 41,37 \%)$, it was unclear whether the type of support was delivered through a group or one-on-one format.

\section{Type of Support}

No studies have reported on interventions that included only one type of support. Instead, the interventions provided a mix of emotional, informational, and appraisal support. A total of 29 studies failed to define a theoretical framework underpinning the intervention.

\section{Underlying Theories}

In total, 12 studies included the following underlying theories, models, or approaches: social learning theory [50,58,67], social comparison theory $[37,68]$, social support theory by La Coursiere [42,69], self-management theory by Bandura [28,70,71], Information-Motivation-Behavioral Skills model $[46,72]$, self-efficacy theory [30,70], person-centered care approach [32,73], stress process model $[31,74]$, the concept of human bonding and social support as defined by Namkoong et al $[34,75]$, and the conceptual framework outlined by Dennis [76] (emotional, informational, and appraisal support).

\section{Outcomes Measures and Impact}

Among the randomized controlled trials $(6 / 41,15 \%)$, the outcomes used were participant openness, trust, motivation, knowledge, self-efficacy, self-care behavior levels, social relationships, emotional distress, depression, mastery, self-esteem, social support, and general well-being [27,28,30-32]. The measures included were the Working Alliance Inventory [27], California Psychotherapy Alliance Scale [27], Patient-Reported Outcome Quality of Life subscales of body change [30], Positive Outlook Self-Efficacy Scale [30], Health Education Impact Questionnaire [30], and Well-being Questionnaire [32]. The randomized controlled trials included in this review reported on the following conditions: diabetes $(2 / 6,33 \%)$ [28,32], HIV $(2 / 6,33 \%)$ [29,30], cancer $(1 / 6,17 \%)$ [27], and stroke $(1 / 6,17 \%)$ [31].

A total of 2 of the 6 randomized controlled trials on diabetes management reported no statistically significant differences between groups for self-efficacy, general well-being, or self-care behaviors (eg, general diet, exercise, and smoking) [28,31]; however, a higher level of disease-specific knowledge was reported in the group of participants receiving web-based peer support [28]. The remaining 4 of the 6 randomized controlled trials reported positive and significant results, including increased feelings of acceptance and respect by others, health service navigation, self-efficacy, social participation, and constructive attitudes and approaches and decreased emotional distress [28,46-48].

In the qualitative studies, some of the positive experiences of participating in an web-based peer support program included increased compassion and improved attitudes toward their condition (ie, people felt that they were not alone in their struggles or that peer support reduced isolation) [38,52], access to information that people could not access through their health care professionals (ie, experiences of people with a similar condition and the gathering of information about a treatment option) $[38,52,60]$, and empowerment (ie, taking an active role in one's condition) [33]. Among these qualitative studies, several barriers and enablers to obtaining peer support were identified. Some of the barriers to participating in the web-based peer 
support program included challenges of timing with other life events, a lack of availability or access, the perception of not fitting in with a web-based group, and the need for more condition-specific content $[33,38,52]$. Enablers to using the program included the use of appropriate language (ie, clear and easy to understand), flexibility or self-pacing, appropriate module length (ie, did not represent a burden to the participant), and the usability of the platform $[38,42,48,50]$. Furthermore, studies have reported that participants viewed web-based support programs as a unique resource that allows them to be engaged in a program from home anonymously $[37,60,65]$. To exemplify some of the web-based peer support interventions described in the studies included in this review, we have presented 2 case examples in Figures 2 and 3.

Figure 2. An example of an article included in this study. De Simoni et al [35] reports on web-based stroke forum.

\section{Talkstroke: Online Forum}

Analysis

Thematic analysis of posts

Outcome measures

Characteristics of participants

Intent for writing a post

Topics of discussion
Extraction of main themes

Request of information

Request of support

Sharing of own experiences 
Figure 3. An example of an article included in this study. Lovatt et al [24] reports on the difference between standard of care and web-based support.

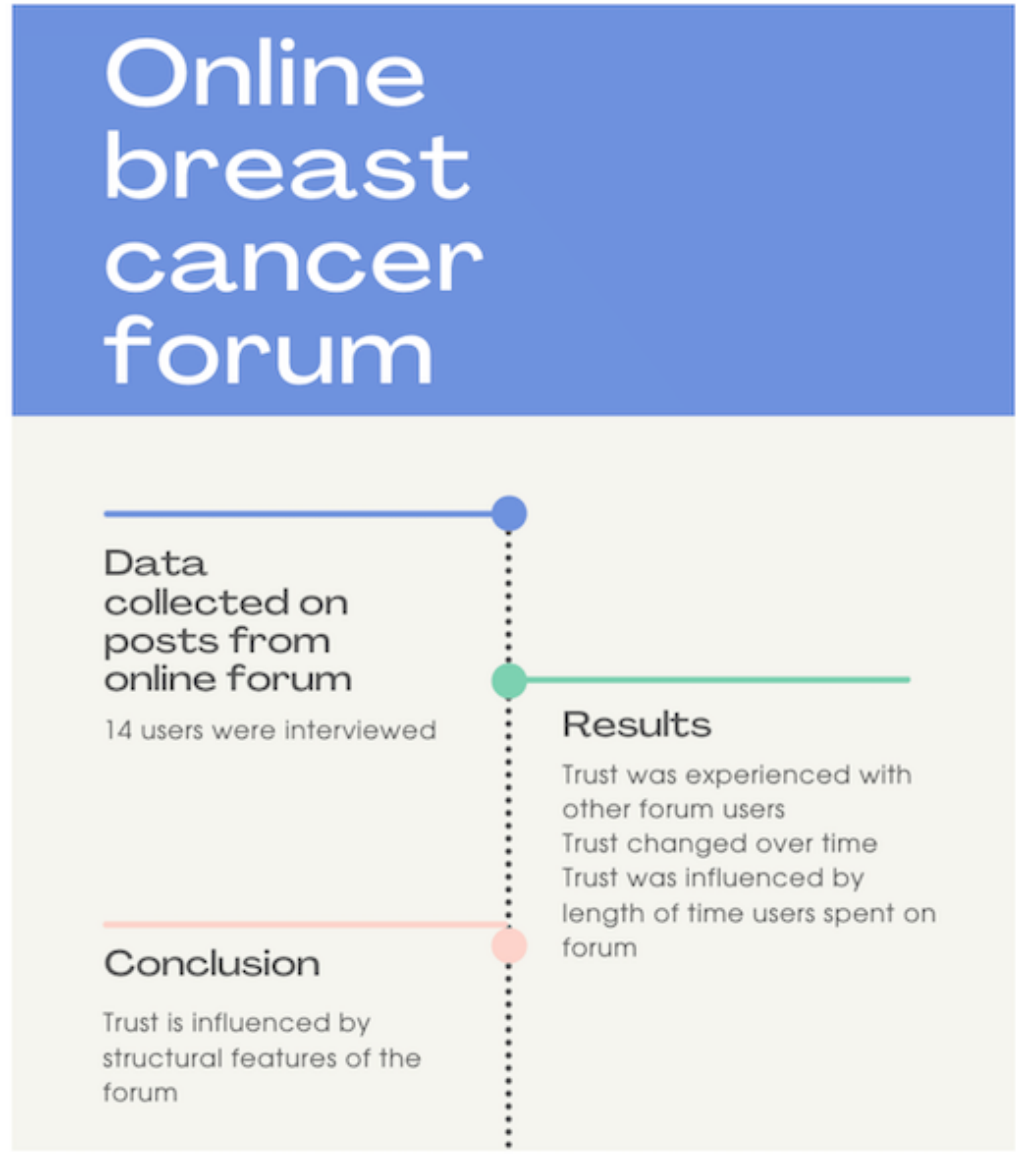

\section{Discussion}

\section{Principal Findings}

\section{Overview}

This scoping review aims to determine what is known from the existing literature about the key characteristics (eg, duration; frequency; delivery setting; type of intervention; type of support provided, including emotional, informational, and appraisal; and underlying theories for the intervention or behavior change techniques or mechanisms) of web-based peer support interventions for adults with chronic conditions. The main findings of this review were as follows: (1) a lack of participant diversity in the included studies, specifically with respect to the conditions studied (ie, the majority of the studies included were related to cancer, cardiovascular disease, and HIV or AIDS) and the exclusion of older participants (ie, the age range for included studies was 19-70 years); (2) few studies used a randomized controlled trial design; (3) over one-third (15/41, $37 \%$ ) of the interventions included involved web-based discussion boards, and just over half $(21 / 41,51 \%)$ of the included studies involved group-type peer support; (4) the interventions provided a mix of emotional, informational, and appraisal support, but the majority of studies did not report on an underlying theory or conceptual framework for the intervention; and (5) in terms of outcomes, among the quantitative studies, 4 of the 6 randomized controlled trials demonstrated increased feelings of acceptance and respect by others, health service navigation, self-efficacy, social participation, and constructive attitudes and approaches and decreased emotional distress [28,46-48], whereas for the qualitative studies, participants reported increased compassion and improved attitudes toward their condition [38,52]. To the best of our knowledge, this is the first scoping review to synthesize evidence on web-based peer support interventions across a variety of chronic conditions.

\section{Patient Characteristics}

Across the 41 included studies, the age range was 19-70 years. Although it is recognized that some conditions are more common among younger individuals (eg, HIV or AIDS), the absence of recent evidence on web-based peer support interventions for individuals aged $\geq 70$ years is noteworthy. For example, in Canada, about $20 \%$ of breast cancers are diagnosed in women aged $<50$ years, whereas almost $30 \%$ are diagnosed in women $\geq 70$ years. Individuals $\geq 70$ years are more likely to be socially isolated and lonely [77], and thus, they have the potential to benefit the most from a web-based peer support intervention. For example, in a pre-post pilot study of a peer-to-peer support program engaging older adults to provide companionship to less-able older persons (mean age 69 years) via home visits and phone calls, Geffen et al [78] demonstrated significantly decreased reporting of reduced social interaction and reduced loneliness in addition to increased levels of self-reported well-being, improved emotional and informational support, increased mood scores, and increased levels of physical activity. 
The findings of this review suggest that there is a need for more studies on web-based peer support interventions for individuals $\geq 70$ years, in these and other specific disease populations, and for improved methods to target these vulnerable groups. Furthermore, Statistics Canada indicates that rates of internet use vary across age groups within the senior population, with $81 \%$ use among older adults aged 65-69 years, compared with $74 \%$ use among those aged 70-74 years, $64 \%$ use among those aged 75-79 years, and $49 \%$ use among those aged $\geq 80$ years [79]. Although it is unclear whether these decreased rates are due to issues related to internet access and/or computer literacy, these potential barriers should be addressed to realize the benefits of web-based peer support (including the benefits outlined in the current review) for older adults with chronic health conditions. In terms of the breadth of chronic diseases included, our results align with a scoping review on peer support for people with chronic conditions in rural areas in terms of identifying studies on a limited range of chronic conditions. Specifically, Lauckner and Hutchinson [12] determined that many studies were related to individuals with diabetes.

\section{Duration and Frequency}

We determined that there was a lack of consistency in terms of reporting intervention characteristics. Similarly, in a systematic review of peer support interventions for individuals with acquired brain injury, cerebral palsy, and spina bifida, members of our research team concluded that experts from relevant disciplines collaborated to develop the peer support interventions, but they did not specify the methods by which the key components of the interventions such as session duration, frequency, and intervention length were chosen or how these decisions were informed. Given this lack of consistency, it is suggested that future studies reporting on web-based peer support interventions consistently use the better reporting of interventions: a Template for Intervention Description and Replication checklist and guide [80]. This guide includes the following items: brief name, why, what, who provided, how, where, when and how much (ie, duration and frequency), tailoring, modifications, and how well. The application of this checklist could promote the replicability of the intervention and an understanding of the program components that are associated with improved outcomes. At the same time, it is important to recognize that the need to better report the intervention duration and frequency does not apply equally to all web-based peer support contexts. Finally, the number of trials included in this review was too small to draw any associations between the frequency of the peer interactions and the duration of the programs and associated outcomes. However, future trials in this area should examine these associations (ie, dose response).

\section{Delivery Setting and Types of Intervention}

Other important aspects of this review were the delivery settings and the types of interventions. In terms of the randomized controlled trials, as previously mentioned, the number included was too small to draw any associations between the delivery setting and the type of interventions and outcomes. Among the studies involving nonexperimental designs, 37\% (15/41) used web-based discussion boards with a group type of intervention.
Group peer-to-peer discussion boards may be particularly valuable, as noted by a qualitative study on the perspectives of individuals with type 1 diabetes using an internet self-management system, as they allow patients to share tips and advice on managing their conditions and provide an opportunity to relate to fellow patients [81]. Similarly, in a qualitative study on one-to-one versus group-based peer support for breastfeeding, Hoddinott et al [82] determined that group-based peer support was more popular, as it normalized breastfeeding in a social environment, which in turn improved participants' sense of well-being. Participants also indicated that the group format in particular assisted women with decision making [82]. The impact of web-based, one-to-one versus group-based peer support could be the focus of future randomized controlled trials.

\section{Types of Support Provided}

In our review, we identified all 3 types of support-emotional (eg, communicating a sense of belonging, inclusivity, and reinforcing the presence of others), informational (eg, asking others for guidance and providing detailed explanations), and appraisal (eg, goal setting and action planning that can provide opportunities for constructive feedback) - across the included studies. A review by Lauckner and Hutchinson [12] determined that the majority of programs provided general social support and support related to the development of new skills (eg, appraising health information using a computer; preparing meals; and improving self-management skills, goal setting and problem solving, and general skills to support lifestyle changes). Although they did not identify the specific constructs of emotional, informational, and appraisal support as we did in our review, there appears to be an overlap between the types of support identified in their review and our review, particularly in the areas of informational support (eg, development of new skills) and appraisal support (eg, goal setting and problem solving).

\section{Underlying Theories for the Intervention}

Only 12 of the 41 studies provided an underlying theory or model or approach, with some of these studies reporting only an underlying approach (ie, person-centered care approach). Previous research suggests that a thorough approach to intervention development, including a clear rationale for the design and development of interventions, is recommended $[83,84]$. Thus, future peer support interventions should implement an underlying theory or model to inform interventions, which in turn would support the intended outcomes of the intervention.

\section{Impact}

Lauckner and Hutchinson [12] determined that of the 9 studies that reported on program outcomes, 8 reported positive outcomes, whereas 1 study reported mixed results. Overall program success, participants valuing the social components of the program, improved activity or weight loss, and participants feeling an increased sense of efficacy were the related positive outcomes reported. Similarly, among the trials included in our review, it was demonstrated that web-based peer support programs resulted in improved social participation, self-efficacy, 
and health-directed activity. Thus, peer support may serve as an important supplement to formal care, as noted by Smith et al [85] in an evaluation of a web-based peer support community intervention. Furthermore, Lauckner and Hutchinson [12] noted that the use of telecommunications with deidentification protocols, such as passwords and pseudonyms, decreased the perceived stigma related to program participation. They also noted that this is particularly important for vulnerable populations. This perspective was noted across many of the included qualitative studies in our review, where participants appreciated the anonymity that a web-based program affords [60,65]. Lauckner and Hutchinson [12] reported that studies that used telecommunications as part of the intervention often provided technical support services to ensure effective program implementation. Similarly, we determined that the availability of technical support was a key enabler for the implementation of web-based peer support interventions. The review by Lauckner and Hutchinson [12] and our review across similar chronic conditions suggests that the impact of face-to-face peer support interventions may be comparable with web-based peer support interventions, with web-based peer support interventions promoting accessibility and potentially reducing the stigma associated with face-to-face interventions.

\section{Limitations}

We acknowledge some limitations of this scoping review. This review did not include primary mental health conditions and a variety of other disabilities. As previously mentioned, interventions that focused on mental illness were excluded from our list of chronic diseases, given that peer support interventions for this group may have unique features not generalizable to other patient populations with chronic disease, and a systematic review of digital peer support interventions for people with lived experience of a serious mental illness has recently been completed [86]. As web-based interventions also relate to computer science and information studies, there are additional databases that could have been included and would likely have identified a separate subfield of studies. Potential databases include IEEE and ACM, and they should be explored in future reviews on web-based interventions. This review did not look at the types of funding each study was provided with, and therefore, we cannot make definitive conclusions on whether interventions were scaled up. Furthermore, this review was limited to English language studies only and the published research literature. As a result, we likely have a bias toward studies from English-speaking countries, and we acknowledge that we likely excluded reports on other available, relevant programs (ie, but not published in peer-reviewed journals). Similarly, we excluded conference abstracts of posters or oral presentations (ie, without an accompanying, published article).

\section{Conclusions}

The results of this review demonstrate that there is a limited, recent high-level evidence (ie, randomized controlled trials) on web-based peer support interventions. Where evidence exists, significant improvements in social participation, self-efficacy, and health-directed activity were demonstrated. However, these trials were limited to 4 conditions only: diabetes, HIV, cancer, and stroke. Thus, we recommend the study of web-based peer support in a much broader range of conditions. We further recommend the use of web-based peer support for older adults (ie, aged $>70$ years) with chronic conditions. We determined that some of the included studies incorporated a theoretical framework, and all forms of support-emotional, informational, and appraisal—were identified in the studies included in this review. Future peer support interventions should implement an underlying theory or model to inform interventions, which in turn would support the intended outcomes of the intervention. Future studies should also consistently report on the intervention characteristics, including the frequency and duration of the intervention, to promote replicability and to draw associations between intervention characteristics and specific outcomes. Overall, the results of this review have identified key gaps in the area of web-based peer support that will serve to inform the development, implementation, and evaluation of future programs.

\section{Acknowledgments}

The authors would like to acknowledge the following contributions of their team: Nigel Barnim for contributing to the level 1 screening process and Mehdi Sabour for assisting with data abstraction.

\section{Conflicts of Interest}

None declared.

\section{Multimedia Appendix 1}

Complete data set.

[XLSX File (Microsoft Excel File), 42 KB-Multimedia Appendix 1]

\section{Multimedia Appendix 2}

Frequency of delivery settings.

[PNG File, 45 KB-Multimedia Appendix 2]

\section{References}


1. How healthy are Canadians? A trend analysis of the health of Canadians from a healthy living and chronic disease perspective. Public Health Agency of Canada. 2016. URL: http://publications.gc.ca/site/archivee-archived.html?url=http://publications. gc.ca/collections/collection 2017/aspc-phac/HP40-167-2016-eng.pdf [accessed 2019-04-03]

2. Mirolla M. The cost of chronic disease in Canada. The Chronic Disease Prevention Alliance of Canada. 2004. URL: http:/ /www.gpiatlantic.org/pdf/health/chroniccanada.pdf [accessed 2019-04-03]

3. Hajat C, Kishore SP. The case for a global focus on multiple chronic conditions. BMJ Glob Health 2018;3(3):e000874 [FREE Full text] [doi: 10.1136/bmjgh-2018-000874] [Medline: 29989034]

4. Gerteis J, Izrael D, Deitz D, LeRoy L, Ricciardi R, Miller T, et al. Multiple chronic conditions chartbook. Agency for Healthcare Research and Quality. 2014. URL: https://www.ahrq.gov/sites/default/files/wysiwyg/professionals/ prevention-chronic-care/decision/mcc/mccchartbook.pdf [accessed 2021-04-30]

5. Tsasis P. Chronic disease management and the home-care alternative in Ontario, Canada. Health Serv Manage Res 2009 Aug;22(3):136-139. [doi: 10.1258/hsmr.2009.009002] [Medline: 19633182]

6. Clarke JL, Bourn S, Skoufalos A, Beck EH, Castillo DJ. An innovative approach to health care delivery for patients with chronic conditions. Popul Health Manag 2017 Feb;20(1):23-30 [FREE Full text] [doi: 10.1089/pop.2016.0076] [Medline: 27563751]

7. de Silva D. Helping people help themselves : a review of the evidence considering whether it is worthwhile to support self-management. The Health Foundation. 2011. URL: https://www.health.org.uk/publications/

evidence-helping-people-help-themselves [accessed 2021-04-30]

8. Kitts J, Beaton B, Cook C, Doiron C, Kendel D, Cooper B. Self-management support for Canadians with chronic health conditions. Health Council of Canada. 2012. URL: https://www.selfmanagementbc.ca/uploads/ HCC SelfManagementReport FA.pdf [accessed 2021-05-03]

9. Heisler M. Overview of peer support models to improve diabetes self-management and clinical outcomes. Diabetes Spectr 2007 Oct 01;20(4):214-221. [doi: 10.2337/diaspect.20.4.214]

10. Economic analysis in peer support: breadth of approaches and implications for peer support programs. Peers for Progress. URL: http://peersforprogress.org/wp-content/uploads/2015/04/150417-economic-analysis-in-peer-support.pdf [accessed 2019-04-03]

11. Wingate L, Graffy J, Holman D, Simmons D. Can peer support be cost saving? An economic evaluation of RAPSID: a randomized controlled trial of peer support in diabetes compared to usual care alone in East of England communities. BMJ Open Diabetes Res Care 2017 Sep;5(1):e000328 [FREE Full text] [doi: 10.1136/bmjdrc-2016-000328] [Medline: 29225890]

12. Lauckner HM, Hutchinson SL. Peer support for people with chronic conditions in rural areas: a scoping review. Rur Rem Health 2016;16(1):3601 [FREE Full text] [Medline: 26943760]

13. Bamuhigire OB. The Healing Power of Self Love. Indiana, United States: iUniverse; 2009:1-504.

14. Johnson J. Number of internet users in Canada from 2000 to 2019. Statista. 2021. URL: https://www.statista.com/statistics/ 243808/number-of-internet-users-in-canada/ [accessed 2019-04-03]

15. World internet users and 2021 population stats. Internet World Stats. URL: https://www.internetworldstats.com/stats.htm [accessed 2019-04-03]

16. Internet in 4 out of 5 households. Statistics Canada. 2010. URL: https://www150.statcan.gc.ca/n1/pub/11-402-X/2012000/ chap/information/information01-eng.htm [accessed 2019-04-03]

17. Munce SE, Shepherd J, Perrier L, Allin S, Sweet SN, Tomasone JR, et al. Online peer support interventions for chronic conditions: a scoping review protocol. BMJ Open 2017 Sep 24;7(9):e017999 [FREE Full text] [doi:

10.1136/bmjopen-2017-017999] [Medline: 28947464]

18. Tricco AC, Lillie E, Zarin W, O'Brien KK, Colquhoun H, Levac D, et al. PRISMA extension for Scoping Reviews (PRISMA-ScR): checklist and explanation. Ann Intern Med 2018 Oct 02;169(7):467-473. [doi: 10.7326/M18-0850] [Medline: 30178033]

19. Chronic diseases. Government of Canada. 2019. URL: https://www.canada.ca/en/public-health/services/chronic-diseases. $\underline{\mathrm{html}}$ [accessed 2019-04-03]

20. Bernell S, Howard SW. Use your words carefully: what is a chronic disease? Front Public Health 2016;4:159 [FREE Full text] [doi: 10.3389/fpubh.2016.00159] [Medline: 27532034]

21. Tricco AC, Antony J, Ivers NM, Ashoor HM, Khan PA, Blondal E, et al. Effectiveness of quality improvement strategies for coordination of care to reduce use of health care services: a systematic review and meta-analysis. Can Med Assoc J 2014 Oct 21;186(15):568-578 [FREE Full text] [doi: 10.1503/cmaj.140289] [Medline: 25225226]

22. Pulcu E, Zahn R, Elliott R. The role of self-blaming moral emotions in major depression and their impact on social-economical decision making. Front Psychol 2013;4:310 [FRE Full text] [doi: 10.3389/fpsyg.2013.00310] [Medline: 23750148]

23. Prestage G, Brown G, Allan B, Ellard J, Down I. Impact of peer support on behavior change among newly diagnosed Australian gay men. J Acquir Immune Defic Syndr 2016 Aug 15;72(5):565-571. [doi: 10.1097/QAI.0000000000001017] [Medline: 27046267]

24. Lovatt M, Bath PA, Ellis J. Development of trust in an online breast cancer forum: a qualitative study. J Med Internet Res 2017 May 23;19(5):e175 [FREE Full text] [doi: 10.2196/jmir.7471] [Medline: 28536093] 
25. Hilliard ME, Sparling KM, Hitchcock J, Oser TK, Hood KK. The emerging diabetes online community. Curr Diabetes Rev 2015;11(4):261-272 [FREE Full text] [Medline: 25901500]

26. O'Riley AA, Rose J, Dalal B. Online support for individuals with spinal cord injuries: an ethnographic investigation. J Spinal Cord Med 2014 Mar;37(2):179-185 [FREE Full text] [doi: 10.1179/2045772313Y.0000000118] [Medline: 24090378]

27. McGill BC, Sansom-Daly UM, Wakefield CE, Ellis SJ, Robertson EG, Cohn RJ. Therapeutic alliance and group cohesion in an online support program for adolescent and young adult cancer survivors: lessons from "Recapture Life". J Adolesc Young Adult Oncol 2017 Jun 05:568-572. [doi: 10.1089/jayao.2017.0001] [Medline: 28581346]

28. Wu CJ, Chang AM, Courtney M, Kostner K. Peer supporters for cardiac patients with diabetes: a randomized controlled trial. Int Nurs Rev 2012 Sep;59(3):345-352. [doi: 10.1111/j.1466-7657.2012.00998.x] [Medline: 22897185]

29. Young SD, Cumberland WG, Lee S, Jaganath D, Szekeres G, Coates T. Social networking technologies as an emerging tool for HIV prevention: a cluster randomized trial. Ann Intern Med 2013 Sep 3;159(5):318-324 [FREE Full text] [doi: 10.7326/0003-4819-159-5-201309030-00005] [Medline: 24026317]

30. Millard T, Agius PA, McDonald K, Slavin S, Girdler S, Elliott JH. The positive outlook study: a randomised controlled trial evaluating online self-management for HIV positive gay men. AIDS Behav 2016 Sep;20(9):1907-1918. [doi: 10.1007/s10461-016-1301-5] [Medline: 26896121]

31. Smith GC, Egbert N, Dellman-Jenkins M, Nanna K, Palmieri PA. Reducing depression in stroke survivors and their informal caregivers: a randomized clinical trial of a web-based intervention. Rehabil Psychol 2012 Aug;57(3):196-206 [FREE Full text] [doi: 10.1037/a0029587] [Medline: 22946607]

32. Linden K, Berg M, Adolfsson A, Sparud-Lundin C. Person-centred, web-based support in pregnancy and early motherhood for women with Type 1 diabetes mellitus: a randomized controlled trial. Diabet Med 2018 Feb;35(2):232-241 [FREE Full text] [doi: 10.1111/dme.13552] [Medline: 29171071]

33. Huber J, Maatz P, Muck T, Keck B, Friederich H, Herzog W, et al. The effect of an online support group on patients treatment decisions for localized prostate cancer: an online survey. Urol Oncol 2017 Feb;35(2):19-28. [doi:

10.1016/j.urolonc.2016.09.010] [Medline: 27810256]

34. Lobchuk M, McClement S, Rigney M, Copeland A, Bayrampour H. A qualitative analysis of "Naturalistic" conversations in a peer-led online support community for lung cancer. Cancer Nurs 2015;38(5):21-31. [doi:

10.1097/NCC.0000000000000207] [Medline: 25254411]

35. De Simoni A, Shanks A, Balasooriya-Smeekens C, Mant J. Stroke survivors and their families receive information and support on an individual basis from an online forum: descriptive analysis of a population of 2348 patients and qualitative study of a sample of participants. BMJ Open 2016 Apr 06;6(4):e010501 [FREE Full text] [doi: 10.1136/bmjopen-2015-010501] [Medline: 27053271]

36. Bender JL, Katz J, Ferris LE, Jadad AR. What is the role of online support from the perspective of facilitators of face-to-face support groups? A multi-method study of the use of breast cancer online communities. Patient Educ Couns 2013 Dec;93(3):472-479. [doi: 10.1016/j.pec.2013.07.009] [Medline: 23928354]

37. Bender JL. The web of care: a multi-method study examining the role of online communities as a source of peer-to-peer supportive care for breast cancer survivors. Dalla Lana School of Public Health, University of Toronto. 2012. URL: https:/ /tspace.library.utoronto.ca/handle/1807/31690 [accessed 2021-04-30]

38. Kemp E, Koczwara B, Butow P, Turner J, Girgis A, Schofield P, et al. Online information and support needs of women with advanced breast cancer: a qualitative analysis. Support Care Cancer 2018 Oct;26(10):3489-3496. [doi: 10.1007/s00520-018-4206-1] [Medline: 29693203]

39. Rising CJ, Bol N, Burke-Garcia A, Rains S, Wright KB. Perceived stress in online prostate cancer community participants: examining relationships with stigmatization, social support network preference, and social support seeking. J Health Commun 2017 Jun;22(6):469-476. [doi: 10.1080/10810730.2017.1304471] [Medline: 28414570]

40. Redman K, Thorne S, Lauck SB, Taverner T. 'What else can I do?': insights from atrial fibrillation patient communication online. Eur J Cardiovasc Nurs 2017 Mar;16(3):194-200. [doi: 10.1177/1474515116678103] [Medline: 28240140]

41. Ahola Kohut S, Stinson J, Forgeron P, Luca S, Harris L. Been There, Done That: the experience of acting as a young adult mentor to adolescents living with chronic illness. J Pediatr Psychol 2017 Oct 01;42(9):962-969 [FREE Full text] [doi: 10.1093/jpepsy/jsx062] [Medline: 28340203]

42. Yli-Uotila T, Rantanen A, Suominen T. Online social support received by patients with cancer. Comput Inform Nurs 2014 Mar;32(3):118-127. [doi: 10.1097/CIN.0000000000000028] [Medline: 24335490]

43. Lewallen A. Linguistic predictors of peer responsiveness in an online cancer support group. Loma Linda University Electronic Theses, Dissertations and Projects. 2013. URL: https://scholarsrepository.llu.edu/etd/133/ [accessed 2021-04-30]

44. Sepah SC, Jiang L, Peters AL. Translating the diabetes prevention program into an online social network: validation against CDC standards. Diabetes Educ 2014 Apr 10;40(4):435-443. [doi: 10.1177/0145721714531339] [Medline: 24723130]

45. Kodatt SA, Shenk JE, Williams ML, Horvath KJ. Leadership qualities emerging in an online social support group intervention. Sex Relation Ther 2014 Nov 01;29(4):467-475 [FREE Full text] [doi: 10.1080/14681994.2014.941346] [Medline: 25642144]

46. Senn TE, Braksmajer A, Coury-Doniger P, Urban MA, Rossi A, Carey MP. Development and preliminary pilot testing of a peer support text messaging intervention for HIV-infected black men who have sex with men. J Acquir Immune Defic Syndr 2017 Feb 01;74 Suppl 2:121. [doi: 10.1097/QAI.0000000000001241] [Medline: 28079722] 
47. Rath L, Vijiaratnam N, Skibina O. Alemtuzumab in multiple sclerosis: lessons from social media in enhancing patient care. Int J MS Care 2017;19(6):323-328 [FREE Full text] [doi: 10.7224/1537-2073.2017-010] [Medline: 29270090]

48. Myrick JG, Holton AE, Himelboim I, Love B. \#Stupidcancer: exploring a typology of social support and the role of emotional expression in a social media community. Health Commun 2016;31(5):596-605. [doi: 10.1080/10410236.2014.981664] [Medline: 26453480]

49. Kim SE, Sweet CM, Gibson E, Madero EN, Rubino B, Morrison J, et al. Evaluation of a digital diabetes prevention program adapted for the Medicaid population: study design and methods for a non-randomized, controlled trial. Contemp Clin Trials Commun 2018 Jun;10:161-168 [FREE Full text] [doi: 10.1016/j.conctc.2018.05.007] [Medline: $\underline{30035241]}$

50. Willis E. The making of expert patients: the role of online health communities in arthritis self-management. J Health Psychol 2014 Dec;19(12):1613-1625 [FREE Full text] [doi: 10.1177/1359105313496446] [Medline: 23988679]

51. Donovan EE, LeFebvre L, Tardif S, Brown LE, Love B. Patterns of social support communicated in response to expressions of uncertainty in an online community of young adults with cancer. J Appl Commun Res 2014 Jul 07;42(4):432-455. [doi: 10.1080/00909882.2014.929725]

52. Brady E, Segar J, Sanders C. Accessing support and empowerment online: the experiences of individuals with diabetes. Health Expect 2017 Oct;20(5):1088-1095 [FREE Full text] [doi: 10.1111/hex.12552] [Medline: 28718928]

53. Guo Y, Goh DH. "I Have AIDS": content analysis of postings in HIV/AIDS support group on a Chinese microblog. Comput Hum Behav 2014 May;34:219-226. [doi: 10.1016/j.chb.2014.02.003]

54. Coulson N. Patterns of engagement with inflammatory bowel disease online support groups: comparing posters and lurkers. Gastroenterol Nurs 2015;38(5):348-353. [doi: 10.1097/SGA.0000000000000131] [Medline: 26166421]

55. Fasciano KM, Souza PM, Braun I, Trevino K. An innovative website in the United States for meeting the emotional and supportive care needs of young adults with cancer. J Adolesc Young Adult Oncol 2015 Mar;4(1):44-49. [doi: 10.1089/jayao.2014.0035] [Medline: 26812430]

56. White K, Gebremariam A, Lewis D, Nordgren W, Wedding J, Pasek J, et al. Motivations for participation in an online social media community for diabetes. J Diabetes Sci Technol 2018 May;12(3):712-718 [FREE Full text] [doi: 10.1177/1932296817749611] [Medline: 29310448]

57. Hess RF, Weinland JA. The life-changing impact of peripartum cardiomyopathy: an analysis of online postings. MCN Am J Matern Child Nurs 2012;37(4):241-246. [doi: 10.1097/NMC.0b013e31824b52ed] [Medline: 22739480]

58. Willis E, Royne MB. Online health communities and chronic disease self-management. Health Commun 2017 Mar;32(3):269-278. [doi: 10.1080/10410236.2016.1138278] [Medline: 27218836]

59. Mitchell SE, Mako M, Sadikova E, Barnes L, Stone A, Rosal MC, et al. The comparative experiences of women in control: diabetes self-management education in a virtual world. J Diabetes Sci Technol 2014 Nov;8(6):1185-1192 [FREE Full text] [doi: 10.1177/1932296814549829] [Medline: 25212580]

60. Harkin LJ, Beaver K, Dey P, Choong K. Navigating cancer using online communities: a grounded theory of survivor and family experiences. J Cancer Surviv 2017 Dec;11(6):658-669 [FREE Full text] [doi: 10.1007/s11764-017-0616-1] [Medline: 28470506]

61. Lewinski AA, Fisher EB. Social interaction in type 2 diabetes computer-mediated environments: how inherent features of the channels influence peer-to-peer interaction. Chronic Illn 2016 Jun;12(2):116-144. [doi: 10.1177/1742395315601414] [Medline: 26304692]

62. Longinetti E, Manoharan V, Ayoub H, Surkan PJ, El-Khatib Z. Utilization of social media and web forums by HIV patients - a cross-sectional study on adherence and reported anxiety level. Prev Med Rep 2017 Jun;6:137-143 [FREE Full text] [doi: 10.1016/j.pmedr.2017.02.009] [Medline: 28316909]

63. Libreri C, Graffigna G. Mapping online peer exchanges on diabetes. Neuropsychological Trends. 2012. URL: https:/ /publicatt.unicatt.it/handle/10807/60496\#.YIwdTLUzayI [accessed 2021-04-30]

64. Henwood R, Patten G, Barnett W, Hwang B, Metcalf C, Hacking D, et al. Acceptability and use of a virtual support group for HIV-positive youth in Khayelitsha, Cape Town using the MXit social networking platform. AIDS Care 2016 Dec;28(7):898-903. [doi: 10.1080/09540121.2016.1173638] [Medline: 27098208]

65. Kohlmann T, Wang C, Lipinski J, Hadker N, Caffrey E, Epstein M, et al. The impact of a patient support program for multiple sclerosis on patient satisfaction and subjective health status. J Neurosci Nurs 2013 Jun;45(3):3-14. [doi: 10.1097/JNN.0b013e31828a4161] [Medline: 23636073]

66. Huber J, Maatz P, Muck T, Keck B, Friederich HC, Herzog W, et al. 365 The impact of an online support group on patients' treatment decisions for localized prostate cancer: an online survey. European Urology Supplements 2015 Apr;14(2):e365. [doi: 10.1016/s1569-9056(15)60360-8]

67. Bandura A, Walters R. Social Learning Theory. Englewood Cliffs, NJ: Prentice-hall; 1977:2-256.

68. Festinger L. A theory of social comparison processes. Hum Relat 2016 Apr 22;7(2):117-140. [doi: 10.1177/001872675400700202]

69. LaCoursiere SP. A theory of online social support. ANS Adv Nurs Sci 2001 Sep;24(1):60-77. [doi: 10.1097/00012272-200109000-00008] [Medline: 11554534]

70. Bandura A. Self-efficacy: toward a unifying theory of behavioral change. Psychol Rev 1977 Mar;84(2):191-215. [Medline: $\underline{847061]}$ 
71. Bandura A. Swimming against the mainstream: the early years from chilly tributary to transformative mainstream. Behav Res Ther 2004 Jun;42(6):613-630. [doi: 10.1016/j.brat.2004.02.001] [Medline: 15081880 ]

72. Fisher JD, Fisher WA, Amico KR, Harman JJ. An information-motivation-behavioral skills model of adherence to antiretroviral therapy. Health Psychol 2006 Jul;25(4):462-473. [doi: 10.1037/0278-6133.25.4.462] [Medline: 16846321]

73. Ekman I, Swedberg K, Taft C, Lindseth A, Norberg A, Brink E, et al. Person-centered care--ready for prime time. Eur J Cardiovasc Nurs 2011 Dec;10(4):248-251. [doi: 10.1016/j.ejcnurse.2011.06.008] [Medline: 21764386]

74. Pearlin L, Aneshensel C, Mullan J, Whitlatch C. Caregiving and its social support. In: Binstock RH, George LK, editors. Handbook of Aging and the Social Sciences. Massachusetts, United States: Academic Press; 1996:283-302.

75. Namkoong K, DuBenske LL, Shaw BR, Gustafson DH, Hawkins RP, Shah DV, et al. Creating a bond between caregivers online: effect on caregivers' coping strategies. J Health Commun 2012;17(2):125-140 [FREE Full text] [doi: 10.1080/10810730.2011.585687] [Medline: 22004055]

76. Dennis C. Peer support within a health care context: a concept analysis. Int J Nurs Stud 2003 Mar;40(3):321-332. [doi: 10.1016/s0020-7489(02)00092-5] [Medline: 12605954]

77. Grenade L, Boldy D. Social isolation and loneliness among older people: issues and future challenges in community and residential settings. Aust Health Rev 2008 Aug;32(3):468-478. [doi: 10.1071/ah080468] [Medline: 18666874]

78. Geffen LN, Kelly G, Morris JN, Howard EP. Peer-to-peer support model to improve quality of life among highly vulnerable, low-income older adults in Cape Town, South Africa. BMC Geriatr 2019 Oct 22;19(1):279 [FREE Full text] [doi: 10.1186/s12877-019-1310-0] [Medline: $\underline{31640576]}$

79. Study: evolving internet use among Canadian seniors. Statistics Canada. 2019. URL: https://www150.statcan.gc.ca/n1/ daily-quotidien/190710/dq190710d-eng.htm [accessed 2021-04-30]

80. Hoffmann TC, Glasziou PP, Boutron I, Milne R, Perera R, Moher D, et al. Better reporting of interventions: template for intervention description and replication (TIDieR) checklist and guide. Br Med J 2014 Mar 07;348:g1687. [doi: 10.1136/bmj.g1687] [Medline: 24609605]

81. Armstrong N, Powell J. Patient perspectives on health advice posted on internet discussion boards: a qualitative study. Health Expect 2009 Sep;12(3):313-320. [doi: 10.1111/j.1369-7625.2009.00543.x] [Medline: 19555377]

82. Hoddinott P, Chalmers M, Pill R. One-to-one or group-based peer support for breastfeeding? Women's perceptions of a breastfeeding peer coaching intervention. Birth 2006 Jun;33(2):139-146. [doi: 10.1111/j.0730-7659.2006.00092.x] [Medline: 16732780]

83. Tilkeridis J, O'Connor L, Pignalosa G, Bramwell M, Jefford M. Peer support for cancer patients. Aust Fam Physician 2005 Apr;34(4):288-289. [Medline: 15861755]

84. French SD, Green SE, O'Connor DA, McKenzie JE, Francis JJ, Michie S, et al. Developing theory-informed behaviour change interventions to implement evidence into practice: a systematic approach using the Theoretical Domains Framework. Implement Sci 2012;7:38 [FREE Full text] [doi: 10.1186/1748-5908-7-38] [Medline: 22531013]

85. Smit D, Vrijsen J, Groeneweg B, Dings A, Peelen J, Spijker J. A qualitative evaluation of the value of an online peer support community for people with depression: Depression Connect. JMIR Preprints . [doi: 10.2196/preprints.25917]

86. Fortuna KL, Naslund JA, LaCroix JM, Bianco CL, Brooks JM, Zisman-Ilani Y, et al. Digital peer support mental health interventions for people with a lived experience of a serious mental illness: systematic review. JMIR Ment Health 2020 Apr 03;7(4):e16460 [FREE Full text] [doi: 10.2196/16460] [Medline: 32243256]

\author{
Abbreviations \\ PHAC: Public Health Agency of Canada \\ PRISMA: Preferred Reporting Items for Systematic Reviews and Meta-Analyses
}

\author{
Edited by G Eysenbach; submitted 08.04.19; peer-reviewed by N Coulson, Z Marshall; comments to author 03.10.19; revised version \\ received 27.10.20; accepted 17.04.21; published 25.05.21 \\ Please cite as: \\ Hossain SN, Jaglal SB, Shepherd J, Perrier L, Tomasone JR, Sweet SN, Luong D, Allin S, Nelson MLA, Guilcher SJT, Munce SEP \\ Web-Based Peer Support Interventions for Adults Living With Chronic Conditions: Scoping Review \\ JMIR Rehabil Assist Technol 2021;8(2):e14321 \\ URL: https://rehab.jmir.org/2021/2/e14321 \\ doi: 10.2196/14321 \\ PMID:
}

(CSaima N Hossain, Susan B Jaglal, John Shepherd, Laure Perrier, Jennifer R Tomasone, Shane N Sweet, Dorothy Luong, Sonya Allin, Michelle L A Nelson, Sara J T Guilcher, Sarah E P Munce. Originally published in JMIR Rehabilitation and Assistive 
Technology (https://rehab.jmir.org), 25.05.2021. This is an open-access article distributed under the terms of the Creative Commons Attribution License (https://creativecommons.org/licenses/by/4.0/), which permits unrestricted use, distribution, and reproduction in any medium, provided the original work, first published in JMIR Rehabilitation and Assistive Technology, is properly cited. The complete bibliographic information, a link to the original publication on https://rehab.jmir.org/, as well as this copyright and license information must be included. 